\title{
Size distribution of near-surface aerosols and its relation to the columnar aerosol optical depths
}

\author{
P. S. Pillai and K. Krishna Moorthy \\ Space Physics Laboratory, Vikram Sarabhai Space Centre, 695022 Thiruvananthapuram, India
}

Received: 27 November 2003 - Revised: 4 June 2004 - Accepted: 24 June 2004 - Published: 3 November 2004

\begin{abstract}
Simultaneous data on Aerosol Optical Depth (AOD) and size segregated, near-surface, aerosol mass concentration was obtained from a Multi wavelength Solar Radiometer (MWR) and Quartz Crystal Microbalance Impactor (QCM), respectively. These were used to examine the association between near-surface aerosol properties and columnar AOD. The spectral AODs were approximated to the Ångström relation $\tau_{p}=\beta \lambda^{-\alpha}$, and the wavelength exponent $\alpha$ and turbidity coefficient $\beta$ have been obtained. In general, $\alpha$ was found to be well associated with the relative abundance of accumulation mode aerosols (estimated from the simultaneous QCM data) while $\beta$ followed the variations of the coarse mode aerosol mass concentration; the association being closer during periods of continental airmass.
\end{abstract}

Key words. Atmospheric composition and structure (Aerosol and particles; Biosphere-atmosphere interactions) - Meteorology and atmospheric dynamics (radiative processes)

\section{Introduction}

Composition and size distribution are fundamentally the most important properties of atmospheric aerosols as far as their direct and indirect radiative effects are concerned (Houghton et al., 2001). Spectral aerosol optical depth (AOD), single scattering albedo, asymmetry factor and phase function are important aerosol properties needed from a radiative transfer point of view (e.g. King et al., 1999; Dubovik et al., 2002), and the size distribution influences most of these. Thus, the information about the size distributions of aerosols is important in the study of the effect of aerosols on atmospheric processes. Most of the atmospheric aerosols are produced close to the Earth's surface, (except the secondary aerosols which are generated from gaseous precursors) and are then distributed spatially by winds, turbulence, diffusion and other atmospheric processes. These processes have a strong bearing on the seasonal variation of solar heating of the surface, prevailing circulations and related bound-

Correspondence to: K. Krishna Moorthy

(k-k-moorthy@eth.net) ary layer processes which influence transfer of flux from the lower regions to higher levels of the atmosphere (Stull, 1988). Nevertheless, near-surface aerosols contribute significantly to the column abundance, except when the transport process becomes significant. Thus, for estimating the radiative impact of aerosols the link between the properties of near-surface aerosols and columnar spectral optical depths needs to be understood. In this paper we examine the association between the characteristics of near-surface aerosols and the spectral characteristic of columnar AODs (and the deduced Ångström parameters) based on independent estimates of both of these parameters at the tropical coastal location Trivandrum $\left(8.55^{\circ} \mathrm{N} ; 77^{\circ} \mathrm{E}, 2 \mathrm{~m} \mathrm{MSL}\right)$ from simultaneous measurements.

\section{Experimental data}

The basic experimental data used for this study comprised of (i) size segregated mass concentrations of near-surface aerosols measured near-real-time regularly using a ten channel Quartz Crystal Microbalance (QCM) Impactor and (ii) columnar spectral AODs (in the visible and near-infrared) estimated from spectral solar extinction measurements made using a ten channel Multi Wavelength Solar Radiometer (MWR). The measurements made during the period January 1999 to December 2000 are used for this study. The QCM provided mass concentration $\mathrm{m}_{c i}$ at ten size bins covering an aerosol diameter $\left(\mathrm{D}_{p i}\right)$ from $25 \mu \mathrm{m}$ to $0.05 \mu \mathrm{m}$; these measurements are taken at nearly hourly intervals from morning to evening, supplemented with diurnal observations at least once a month (Pillai and Moorthy, 2001 for the details) for characterizing near-surface aerosols. The MWR has been in regular operation since 1985 as part of a long-term scientific program, making spectral AOD estimates at 10 wavelengths $380,400,450,500,600,650,750,850,935$ and $1025 \mathrm{~nm}$ (Moorthy et al., 1997 for details) on clear days. As the MWR requires unobstructed solar visibility for at least three hours for AOD estimation, the AOD data are less frequent, particularly during monsoon seasons. As a result we had only 37 days of simultaneous AOD and QCM during the study period. 

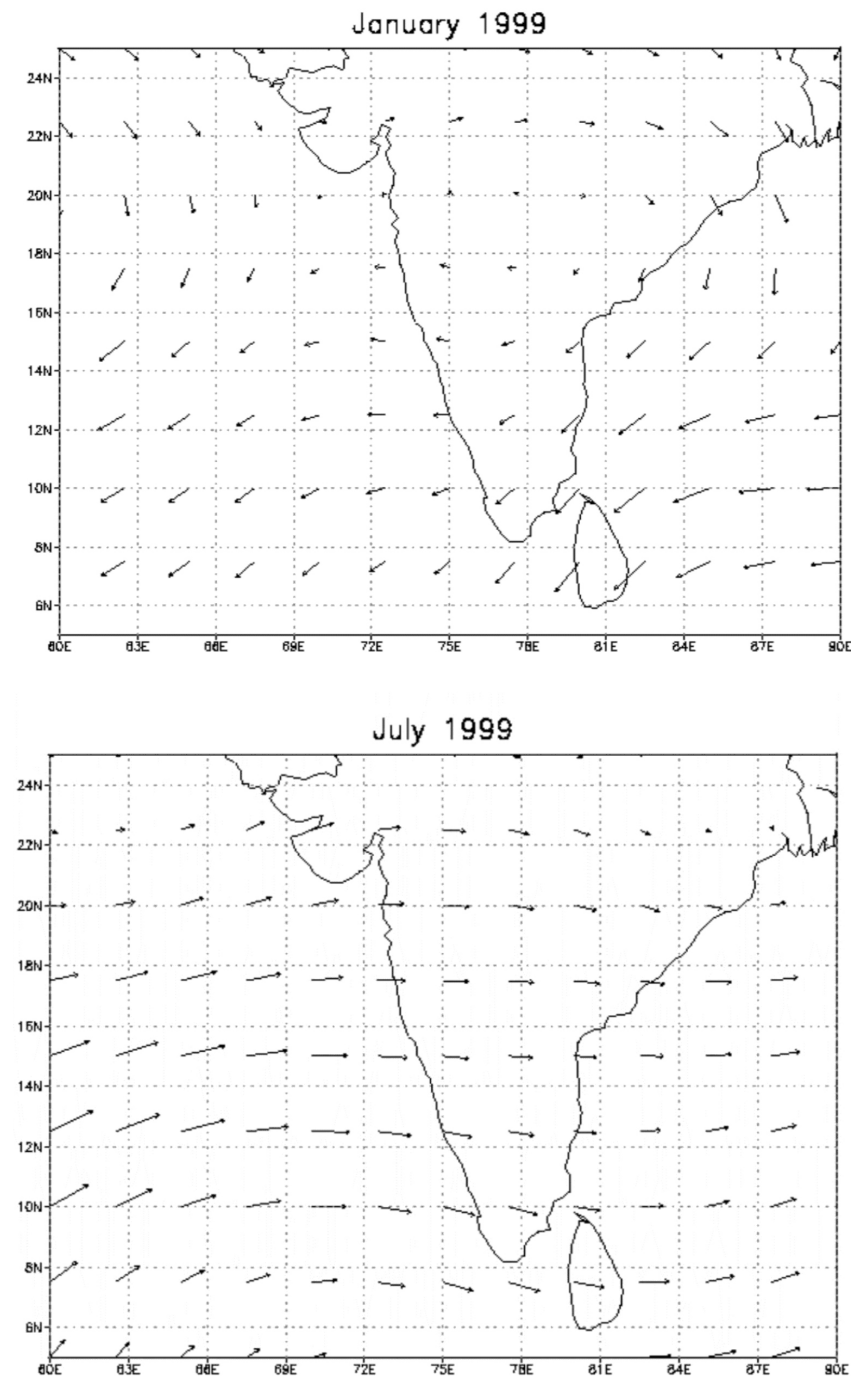

Fig. 1. Prevailing mean wind pattern at $850 \mathrm{mb}$ for the month of January 1999 and July 1999.

\section{Analysis}

3.1 Estimation of accumulation and coarse mass concentrations from QCM

The QCM provides near-real-time measurements of size segregated mass concentration as well as total mass concentration $\left(\mathrm{M}_{t}\right)$ such that

$M_{t}=\sum_{i=2}^{10} m_{c i}$,

where $\mathrm{m}_{c i}$ is the size segregated mass concentration corresponding to each size bin; the first stage is excluded in the summation as the upper cutoff the first stage is not known.

A classification of the size segregated mass concentration into accumulation (particle diameter $<1 \mu \mathrm{m}$ ) and coarse mode (particle diameter $>1 \mu \mathrm{m}$ ) was taken in view of the distinct production mechanisms, and, radiative and environmental impacts of these two types of aerosols. Moreover, being a coastal station, it is logical to consider two potential source mechanisms at this station, one land based and the other of marine origin. The characteristics of these are known to be different. The marine aerosols will mostly lie in the super micron range (Moorthy et al., 2003). The study of the submicron range aerosols are important because of their longer residence times and also because these aerosols contribute more to the scattering and indirect radiative forcing through clouds (Charlson et al., 1987; Toon, 2000). On the other hand, the concentration and size spectrum of sea-spray aerosols strongly depend on the wind speed over oceans (e.g. Lovett, 1978; Exton et al., 1985) and being heavier sea-spray aerosols, their lifetime is shorter and hence important closer to the source regions. For the configuration of the QCM the accumulation mode mass concentration, $M_{a}=\sum_{i=7}^{10} m_{c i}$ and coarse mode aerosol concentration, $M_{c}=\sum_{i=2}^{6} m_{c i}$ are estimated.

\subsection{Retrieval of AOD from MWR}

The MWR provides measurements of directly transmitted, ground reaching solar flux at narrow wavelengths as a function of solar zenith angle. From these measurements, the atmospheric optical depths at the different wavelength are deduced by the Langley plot technique (e.g. Shaw, 1973). Subtracting the contribution due to molecular scattering and absorption from the atmospheric optical depth, the aerosol optical depths are estimated at all ten wavelengths. The details of application of this technique to the MWR data are described in several earlier papers (Moorthy et al., 1997, 1999) and hence are not repeated here. The typical error in the aerosol optical depth estimates varied from 0.01 to 0.02 . This is the error propagated from the error due to the optical depth contributed by molecular scattering and absorption.

\section{Prevailing airmass types}

The station Trivandrum is under the influence of two airmass types during any year, associated with the seasonal changes in the synoptic conditions associated with Indian monsoon (Das, 1986; Asnani, 1993). During the period November to March/April, the (lower tropospheric) synoptic winds are directed from northeast of the station, passing over the continental landmass of India, constituting a "Continental (C) air mass". The pattern almost reverses during May/June to September of the year. During this period the synoptic circulations change to strong north-westerlies /westerlies directed from the Arabian Sea, constituting a "marine (M) airmass". The mean prevailing wind pattern at $850 \mathrm{hPa}$ (representative months of two season) for January and July 1999 is shown in Figs. 1a,b (from the NCEP/NCAR reanalysis (Kalnay et al., 1996)). The prevailing wind during January 1999 , which is representing the continental airmass period, is north-easterly (Fig. 1a) while during July 1999 it is southwesterly (Fig. 1b). During the continental airmass period the winds are generally weak and a long, dry period of nearly 
three months prevails during this period at the station (much longer nearly five months over the upwind continental India); RH becomes very low and the diurnal variation of the surface temperature has the largest amplitude $\left(10^{\circ} \mathrm{C}\right.$ or more $)$ during this season (Pillai and Moorthy, 2001). On the other hand during the marine air mass period the rainfall becomes intense and widespread, and the station receives $\sim 70 \%$ of its annual rainfall of $\sim 1800 \mathrm{~mm}$ during this season. The diurnal amplitude of temperature variation becomes very small $\left(<6\right.$ to $8^{\circ} \mathrm{C}$ ) and the RH goes to higher values. In addition to these two contrasting air masses, the station also experiences regular land/sea breeze activity, which is conscipicious during the continental airmass period. More details are given in Pillai and Moorthy (2001). Our results are examined in light of the above scenario.

\section{Results}

5.1 Spectral AODs and their association with near-surface aerosol features Ångström parameters

The AOD spectra contain information of the columnar size distribution of aerosols as they are related through

$\tau_{p \lambda}=\int_{r_{1}}^{r_{2}} \int_{0}^{h} \pi r^{2} Q_{\text {ext }}(r, \lambda, m) n(r) d r d h$,

where $\tau_{p \lambda}$ is the aerosol optical depth, Qext is the Mie extinction efficiency parameter (dependent on particle size , refractive index and wavelength), $\mathrm{n}(\mathrm{r})$ is the number size distribution, and $r_{1}$ and $r_{2}$ are the lower and upper radii limits. $Q_{\text {ext }}$ increases from a low value for small values of $r / \lambda$, to reach a peak value $(\sim 4)$ for $r \sim \lambda$ and then decreases asymptotically to 2 for higher values of $r$ (McCartney, 1976). Thus, maximum contribution to $\tau$ comes from particles in a size distribution whose radii are comparable to the wavelength of the radiation. The high values of AOD at shorter wavelengths thus imply higher concentration of smaller particles. A simpler way of expressing the wavelength dependence of $\tau$ is through the Ångström relation (Ångström, 1964) given by

$$
\tau_{p \lambda}=\beta \lambda^{-\alpha}
$$

where $\beta$ is the Ångström turbidity coefficient (equal to $\tau_{p}$ at $\lambda=1 \mu \mathrm{m})$ and $\alpha$ the wavelength exponent. The Angström exponent gives a general idea of the particle size distribution being a measure of the relative dominance of accumulation mode aerosols. The constant $(\beta)$ (equals aerosol optical depth at $1 \mu \mathrm{m}$ ) substantially depends on the total aerosol loading and thus has a bearing on coarse mode aerosol particles. By evolving a least-square fit to Eq. (3) to the AOD spectra obtained from the MWR, $\alpha$ and $\beta$ are evaluated. Generally most of the AOD spectra confirmed fairly well to Eq. (3) with a correlation coefficient $>0.67$ (significant at $\mathrm{P}=0.05$ ). (However, some spectra, particularly during May to August 1999 and July 2000, showed greater deviation from

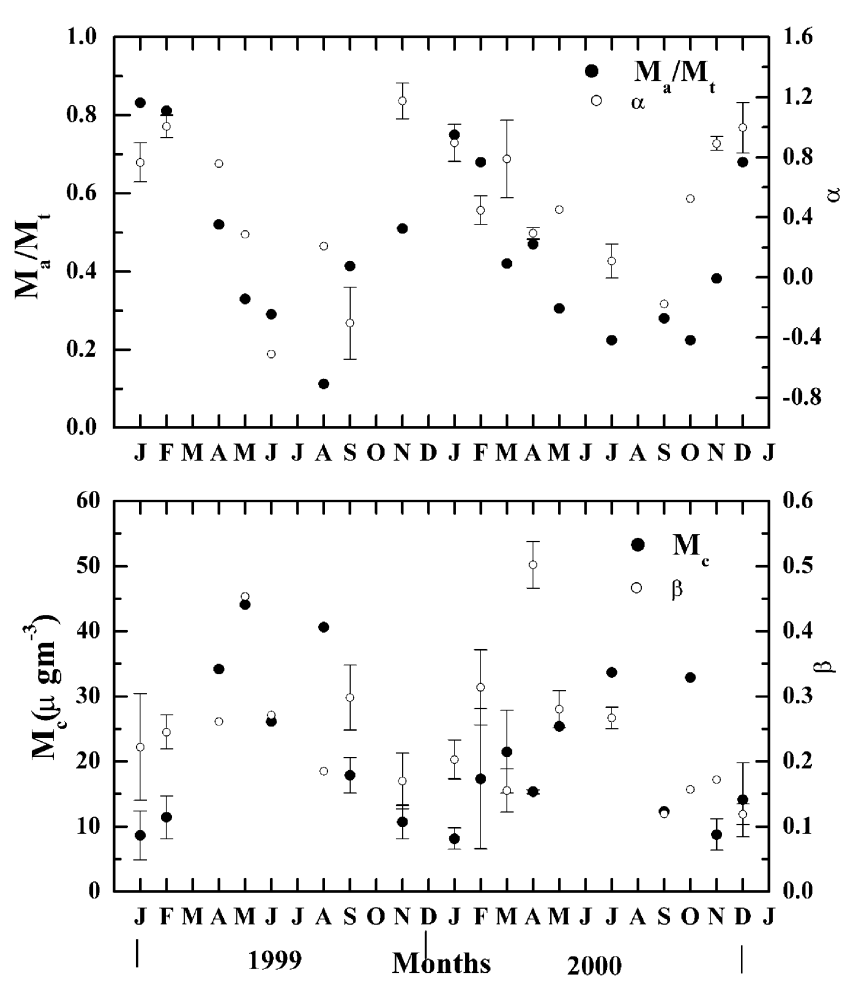

Fig. 2. Annual variation of Ångström parameters, $\alpha$ along with the ratio of accumulation mode aerosol to total aerosol mass concentration (top panel), and $\beta$ along with the coarse mode aerosol mass concentration $\left(\mathrm{M}_{t}\right)$ (bottom panel).

the power law.) Such estimates of $\alpha$ and $\beta$ were made for each of the daily mean AOD spectra and grouping them by the month and averaging, the monthly mean values of $\alpha$ and $\beta$ are deduced.

The variations of $\alpha$ and $\beta$ are examined in Fig. 2 in association with the features of the near-surface aerosols, with $\alpha$ in the top panel and $\beta$ in the bottom. In view of the fact that $\alpha$ is an indicator of the relative abundance of accumulation aerosols in the size spectrum and $\beta$ that of the total aerosol burden, the former is compared with $\mathrm{M}_{a} / \mathrm{M}_{t}$ and the latter with $\mathrm{M}_{c}$ in Fig. 2.

The variation of $\alpha$ and $\beta$ are represented by the open circles, while the dark solid points represent the respective nearsurface parameters. The vertical bars are the standard deviations of the ensemble mean. A similarity in the nature of variations of $\alpha$ and $\mathrm{M}_{a} / \mathrm{M}_{t}$ as well as $\beta$ and $\mathrm{M}_{c}$, is clearly discernible during the months from December to May, when the airmass type is mainly continental $(\mathrm{C})$. This feature is consistent in both years. However, during the marine (M) airmass season, the association weakens. This indicates that the relative abundance (mass concentration) of submicron aerosols near the surface significantly influences the spectral variation of columnar AOD during the period of "C" airmass, whereas the AOD at the near IR wavelengths are strongly influenced by the mass concentration of supermicron aerosols. 


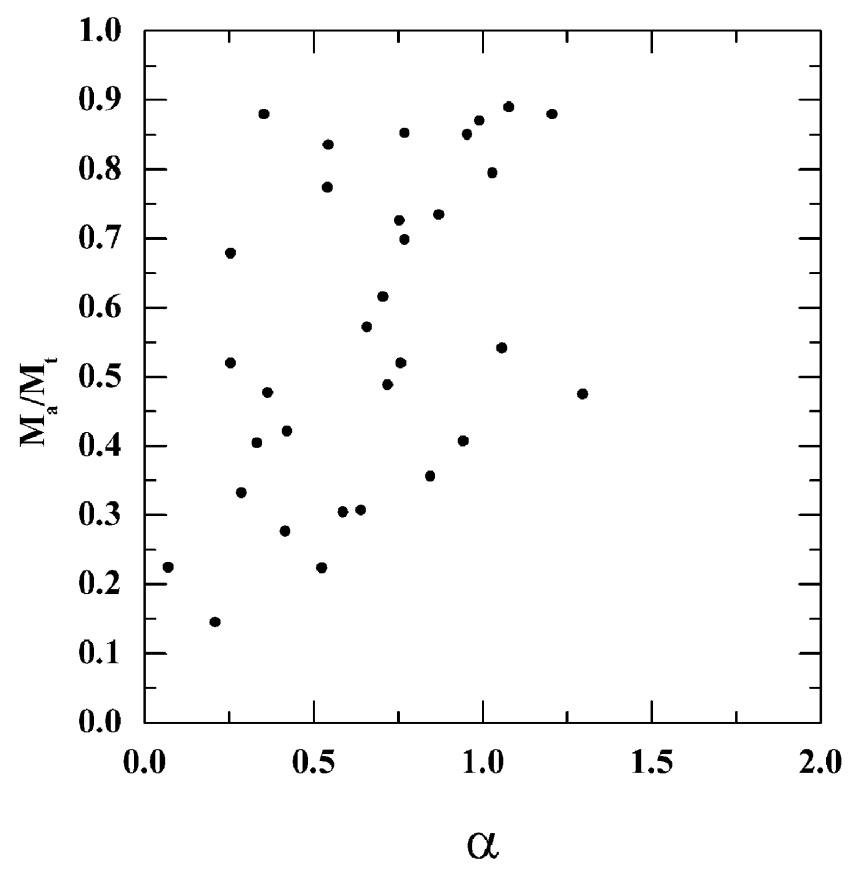

Fig. 3. Scatter plot of $\mathrm{M}_{a} / \mathrm{M}_{t}$ along with $\alpha$.

\section{Discussions}

During the continental airmass period, the value of $\alpha$ as well as $\mathrm{M}_{a} / \mathrm{M}_{t}$ are relatively high compared with that for the marine air mass period. The Ångström exponent $\alpha$ lies generally in the range 0.45 to 1.18 during this period, with a mean value of $0.87 \pm 0.08$; while it is in the range 0.11 to 0.76 with a mean value of $0.34 \pm 0.07$, indicating a considerable flattening of the size spectra. During the Indian Ocean Experiment (INDOEX), based on Sun photometer measurements, Satheesh et al. (1999) have reported $\alpha$ to be in the range of 1.0 and 1.55 during the January to March period ( $\mathrm{C}$ air mass period) over the tropical Indian Ocean. Moorthy et al. (1999) also reported high values of $\alpha(0.94)$ around the coastal Arabian Sea and at Trivandrum during January to March of 1998 and 1999. Jayaraman et al. (2001) reported the wavelength exponent $\alpha$ to be in the range of 1.3 to 1.7 in the Arabian Sea and is in the range of 0.5 to 0.7 over the pristine region (Southern Hemisphere). The results of the present study are in line with these when the air mass type is continental, while they deviate considerably during the $\mathrm{M}$ air mass period.

The large diurnal heating (with the maximum to minimum temperature differing by $\sim 10$ to $15^{\circ} \mathrm{C}$ ), along with the scanty precipitation (180 to $300 \mathrm{~mm}, 10$ to $15 \%$ of the annual) prevailing during the $\mathrm{C}$ air mass period results in a large apportionment $(>50 \%)$ of the incident solar energy to sensible heat flux ( 150 to $200 \mathrm{Wm}^{-2}$ ). Consequently, strong thermal convections occur over the land during this season. Studies at Trivandrum (Kunhikrishnan et al., 1993) have shown that the maximum convective turbulence (due to sensible heat flux) at Trivandrum occurs during the January to March period. The strong convective turbulence provides a thorough verti- cal mixing of the aerosols and other species, which might result in a better vertical homogeneity in their properties during this season. The strong convective eddies provide a means for efficient vertical transport of continental aerosols in this season and an effective exchange between the mixed layer and free troposphere. The smaller aerosols with less inertia and larger surface area (for a given mass) are more influenced by these buoyant forces and become distributed in the column. A scatter plot (Fig. 3) between $\mathrm{M}_{a} / \mathrm{M}_{t}$ and $\alpha$ shows a fairly good association between the two with a correlation of about +0.49 , despite the scatter. Aircraft measurements over the tropical Indian Ocean, downwind of Trivandrum during the winter season, have reported the aerosol layer extending beyond $\approx 3 \mathrm{~km}$ (Ramanathan et al., 2001) with an abundance of accumulation aerosols. Seasonal variations of mixing region aerosol optical depth estimated from Continuous Wave Lidar measurements showed a prominent winter peak (Parameswaran et al., 1998). Larger particles, on the other hand, will be more confined to lower heights. The absence of precipitation and the extended altitude distribution provide a longer atmospheric residence time for the accumulation aerosols, and hence a larger abundance. However, insitu formation of accumulation aerosols at higher altitudes and long-range transport of fine dust at higher levels, are known to produce elevated aerosol layers at 3-4 km (Müller et al., 2001), and these will also contribute to the AOD spectra and $\alpha$. This would lead to the scatter of points in Fig. 3 .

As the airmass shifts to marine, the increased humidity in the marine airmass and deeper convection are conducive for frequent cloud formation, thereby reducing the solar insolation and sensible heat flux. The clouds also favour in-cloud scavenging of aerosols (at higher altitudes) and even if not removed by precipitation, they grow in size due to frequent cycling (Pruppacher and Klett, 1978). Thus, the aerosol number size spectrum would flatten at higher altitudes. This may not be manifesting so strongly near the surface, where the source strength is high and hence the near-surface aerosol size distribution does not show dramatic changes initially. But the AOD spectra depend on the columnar properties and hence would start changing. As the monsoon advances, the strong westerly winds bring a large influx of coarse marine aerosols leading to flatter aerosol spectra. The extensive rainfall would lead to wet removal of aerosols at the cloud level. Based on MWR observations over Trivandrum, Moorthy et al. (1991) have shown the AOD spectra to be flatter and the columnar size distributions to be significantly bimodal during this season. Thus, the relation between the near-surface aerosols and columnar optical depth is not well associated during the marine airmass period.

\section{Conclusions}

1. AOD spectra are steeper during the $\mathrm{C}$ airmass period. The variation of Ångström wavelength exponent $\alpha$ follows closely to that of the relative abundance of accumulation mode aerosols during the $\mathrm{C}$ airmass period. 
2. AOD at the near IR wavelength follow the variation of coarse mode aerosol mass concentration.

3. When the airmass is continental, convective turbulence dominates and the column and surface properties are well associated. When the airmass changes to marine the vertical homogeneity is reduced and the column properties deviates from the surface properties. These observations have general importance while modelling aerosol regionally for radiative forcing calculations.

Acknowledgements. This work was carried out as a part of Aerosol Climatology Project of ISRO-GBP. The authors acknowledge the useful contributions by Mr. S. Suresh Babu and Mr. Auromeet Saha in obtaining some of the data used in this study. The NCEP/NCAR reanalysis is provided by the NOAA-CIRES Climate Diagnostics Center, Boulder, Colorado from their website http://www.cdc.noaa.gov.

Topical Editor O. Boucher thanks two referees for their help in evaluating this paper.

\section{References}

Angström, A.: The parameters of atmospheric turbidity, Tellus., 16, 64-75, 1964.

Asnani, G. C.: Tropical Meteorology, Vol .1, Published by G. C. Asnani, C/o Indian institute of Tropical Meteorology, Pune, India, 1993.

Charlson, R. J., Lovelock, J. E., Andreae, M. O., Warren, S. G.: Oceanic phytoplankton atmospheric sulfur, cloud albedo and climate, Nature, 326, 655-661, 1987.

Das, P. K.: Monsoons. Fifth IMO lecture, WMO, No-613, World Meteorological Organisation, 1986.

Dubovik, O., Holben, B., Eck, T. F., Smirnov, A., Kaufman, Y. J., King,M. D., Tanre, D., and Slutsker, I.: Varaibility of absorption and optical properties of key aerosol types observed in world wide locations, J. Atmos. Sci., 59, 590-608, 2002.

Exton, H. J., Latham, J., Park, P. M., Perry, S. J., Smith, M. H., Allan, R. R.: The production and dispersal of marine aerosol, Q. J. R. Meteorol. Soc., 111, 817-837, 1985.

Houghton, J. T., Ding, Y., and Griggs, D. J. et al.: IPCC: Climate Change 2001-the scientific basis, Intergovernmental Panel on Climate Change, Cambridge University Press, 2001.

Jayaraman, A., Satheesh, S. K., Mitra, A. P., Ramanathan, V.: Latitude gradient in aerosol properties across the Inter Tropical Convergence Zone: Results from the joint Indo-US study onboard Sagar Kanya, Curr. Sci., 80, 128-137, 2001.

Kalnay, E., Kanamitsu, M., Kistler, R., and Collins, W. et al.: "The NCEP/NCAR reanalysis 40- year project”, Bull. Am. Meteorol. Society, 77, 437-471, 1996.

King, M. D., Kaufman, Y. J., Tanre, D., and Nakajima, T.: Remote sensing of tropospheric aerosols from space: Past, Present, and future. Bull. Amer. Meteor. Soc., 80, 2229-2259, 1999.

Kunhikrishnan, P. K., Gupta, S. K., Ramachandran, R., Prakash, J. W. J., Nair, K. N.: Study on thermal internal boundary layer structure over Thumba, India, Ann. Geophys., 11, 52-60, 1993.
Lovett, R. F.: Quantitative measurement of airborne sea-salt in the North Atlantic. Tellus, 30, 358-364, 1978.

Mc Cartney, E. J.: Optics of the Atmosphere, John Wiley, New York, 135-136, 1976.

Moorthy, K. K., Nair, P. R., Murthy, B. V. K.: Size distribution of coastal aerosols: Effect of local sources and sinks, J. Appl. Metereol., 30, 844-852, 1991.

Moorthy, K. K., Satheesh, S. K., Murthy, B. V. K.: Investigations of marine aerosols over the tropical Indian Ocean, J. Geophys. Res., 102, 18 827-18 842, 1997.

Moorthy, K. K., Saha, A., Niranjan, K., and Pillai, P. S.: Optical properties of atmospheric aerosols over the Arabian Sea and Indian Ocean: North-South contrast across the ITCZ, Curr. Sci., 76, 956-960, 1999.

Moorthy. K. K, Pillai, P. S., and Babu, S. S.: Influence of Changes in the Prevailing Synoptic Conditions on the Response of Aerosol Characteristics to Land/Sea Breeze Circulations at a Coastal Station. Boundary-Layer Meteor. 108, 145-161, 2003.

Muller, D., Franke, K., Wagner, F., Althausen, D., Ansmann, A, Heintzenberg, J.: Vertical profiling of optical and physical particle properties over the tropical Indian Ocean with six-wavelength lidar 1. Seasonal cycle, J. Geophys. Res.,106, 28 567-28 575, 2001.

Parameswaran, K., Rajan, R., Vijayakumar, G., Rajeev, K., Moorthy, K. K., Nair, P. R., and Satheesh, S. K.: Seasonal and long term variations of aerosol content in the atmospheric mixing region at a tropical station on the Arabian sea-coast, J. Atmos. Sol. Terr. Phys., 60, 17-25, 1998.

Pillai, P. S. and Moorthy, K. K.: Aerosol mass-size distributions at a tropical coastal station, Response to Mesoscale and Synoptic Processes, Atmos. Environ., 35, 4099-4112, 2001.

Pruppacher, H. R. and Klett, J. D.: Microphysics of clouds and Precipitation, Reidel Publishing Co., USA, 193-195, 1978.

Ramanathan, V.,Crutzen, P. J., Lelieveld, J., Mitra, A. P., Althausen, D., Anderson, J., Andreae, M. O., Cantrell, W., Cass, G. R., Chung, C. E., Clarke, A. D., Coakley, J. A., Collins, W. D., Conant, W. C., Dulac, F., Heintzenberg, J., Heymsfield, A. J., Holben, B., Howell, S., Hudson, J., Jayaraman, A., Kiehl, J. T., Krishnamurti, T. N., Lubin, D., McFarquhar, G., Novakov, T., Ogren, J. A., Podgorny, I. A., Prather, K., Priestley, K., Prospero, J. M., Quinn, P. K., Rajeev, K., Rasch, P., Rupert, S., Sadourny, R., Satheesh, S. K., Shaw, G. E., Sheridan, P., and Valero, F. P. J.: Indian Ocean Experiment: An integrated analysis of the climate forcing and effects of the great Indo-Asian haze, J. Geophys. Res., 106, 28 371-28 398, 2001.

Satheesh, S. K., Ramanathan, V., Lones, X. I., Lobert, J. M., Podgorny, I. A., Prospero, J. M., Holben, B. N., Loeb, N. G.: A model for the natural and anthropogenic aerosols over the tropical Indian Ocean derived from Indian Ocean Experiment data, J. Geophy. Res., 104, 27 421-27 440,1999.

Shaw, G. E., Reagen, J. A., Herman, B. M.: Investigations of atmospheric extinction using direct solar radiation measurements made with a multiple wavelength radiometer, J. Appl. Meteorol., 12, 374, 1973.

Stull, R. B.: An introduction to boundary layer meteorology, Kluwer Academic Publishers, The Netherlands, 1988.

Toon.B. O: How Pollution Suppresses Rain, Science, 287, 17631764, 2000. 